\title{
Accumulation and Long-Term Behavior of Radiocaesium in Tropical Plants
}

\author{
C. Carvalho, B. Mosquera, R. M. Anjos, N. Sanches, J. Bastos, K. Macario, and R. Veiga \\ Instituto de Física, Universidade Federal Fluminense, Av. Gal Milton Tavares de Souza s/n, Gragoatá, Niterói, RJ, Brazil, CEP $24210-346$
}

\section{Received on 18 March, 2006}

\begin{abstract}
The accumulation and distribution of ${ }^{40} K$ and ${ }^{137} C s$ in tropical plant species were studied through measurements of gamma-ray spectra from mango, avocado, guava, pomegranate, chili pepper, papaya and manioc trees. Our goal was to infer their differences in the uptake and translocation of ions to the aboveground plant parts and to establish the suitability of using radiocaesium as a tracer for the plant uptake of nutrients such as $K^{+}$.
\end{abstract}

Keywords: ${ }^{137} \mathrm{Cs}$ and ${ }^{40} \mathrm{~K}$ distributions; Tropical trees

\section{INTRODUCTION}

In recent years, there has been a growing interest in the evaluation of nutrient fluxes and radioactive contaminants in forest and agricultural ecosystems [1-5]. For being chemically similar to available nutrients in soil (such as potassium), radiocaesium is absorbed by plants, entering the food chain and therefore representing a significant pathway of human radiation exposure. Thus, in order to contribute to the understanding of the relative behavior of $\mathrm{K}^{+}$and $\mathrm{Cs}^{+}$ions, the purpose of this work was to examine the concentration levels of ${ }^{137} \mathrm{Cs}$ and ${ }^{40} \mathrm{~K}$ in several tropical plants. The plants were analyzed within the context of a radiological or nuclear accident, investigating the ${ }^{137} \mathrm{Cs}$ contamination by root uptake from contaminated soil. Additionally, two of the plants were transferred to uncontaminated soil (i.e. soil free from the specific ${ }^{137} \mathrm{Cs}$ contamination caused by the radiological accident) in such way that the main source of the contamination of new leaves and fruits is the fraction of the available radiocaesium in the body of the plant. Biological half-lives of ${ }^{137} \mathrm{Cs}$ for this second situation, and analysis of ${ }^{137} \mathrm{Cs}$ and ${ }^{40} \mathrm{~K}$ distributions throughout these tropical plants are also shown in this paper.

\section{MATERIAL AND METHODS}

Samples of soils, roots, trunks, twigs, leaves and edible parts were collected from mango (Mangifera indica), avocado (Persea americana), guava (Psidium guajava), pomegranate (Punica granatum), chili pepper (Capsicum frutescens), papaya (Carica papaya) and manioc (Manihot esculenta) trees. These plants used to be cultivated together at one of the sites where the Goiânia radiological accident occurred [6]. Additionally, chili pepper and pomegranate trees were transplanted to another site with uncontaminated soil. Samples of green and red pepper, and pomegranate were collected over one and three years, respectively. At the end of these periods, samples of root, trunk, twig, leaves and fruit of these plants were also analyzed.

Sample preparation and analysis were carried out at the Laboratory of Radioecology (LARA) of the Physics Institute of the Universidade Federal Fluminense. The amount of ${ }^{137} \mathrm{Cs}$ and ${ }^{40} \mathrm{~K}$ in the samples was determined by standard gammaray spectroscopy using $\mathrm{HPGe}$ and $\mathrm{NaI}(\mathrm{Tl})$ detectors. Fig. 1 shows a typical spectrum from an analyzed sample. Technical details of sample preparation and analysis can be obtained in references [1-4].

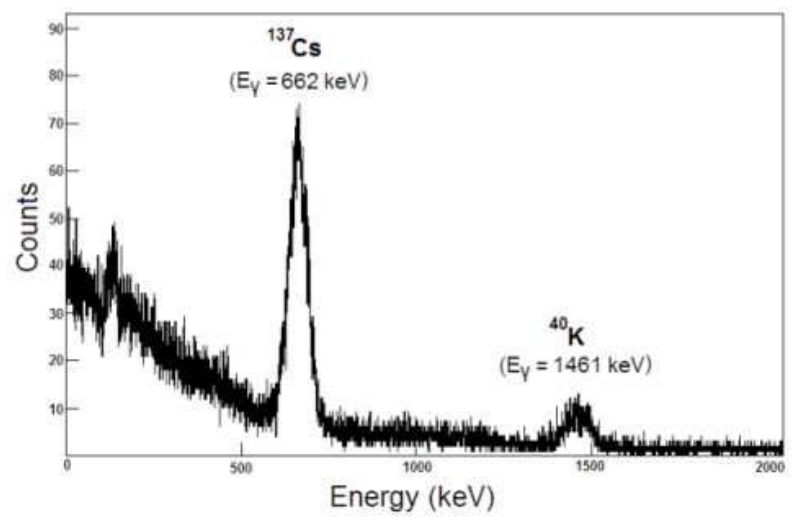

FIG. 1: Typical spectrum of a analyzed sample obtained with the $\mathrm{NaI}(\mathrm{Tl})$ detector during a counting period of $5.8 \times 10^{4}$ seconds.

\section{RESULTS}

Available information in the literature show that potassium can be readily absorbed by plant roots from soil and can be translocated to the aboveground plant parts, such as twigs, leaves, flowers and fruits. Similarly to potassium, caesium has a high mobility within a plant, exhibiting the highest values of concentration in the growing parts of the tree: fruits, leaves, twigs, barks and the outer growth layers [1-5]. In this way, the results presented in Table 1 for the mean values of ${ }^{137} \mathrm{Cs}$ and ${ }^{40} \mathrm{~K}$ concentrations in some compartments of tropical plants contaminated by caesium suggests that tissues with low $\mathrm{K}$ concentrations (on a dry weight basis) have also low Cs concentration. On the other hand, the results shown in this table indicate that only for wood trees contaminated by caesium, both ${ }^{137} \mathrm{Cs}$ and ${ }^{40} \mathrm{~K}$ have simultaneously higher concentrations in the younger parts than in the older parts. This result implies that the Cs distribution within plants of some species (such as manioc) does not behave exactly as that of $\mathrm{K}$ and, therefore, in such cases, ${ }^{137} \mathrm{Cs}$ could not be a good tracer of plant nutrients. For Papaya trees, although they do not follow the same pattern of wood trees, $\mathrm{Cs}$ and $\mathrm{K}$ have a similar behavior. Additionally, in what concerns the decontamina- 
tion process, when some tropical trees were transplanted to a site with uncontaminated soil, there was an inversion of ${ }^{137} \mathrm{Cs}$ levels in the different organs of the plant. The youngest parts present specific ${ }^{137} \mathrm{Cs}$ activity lower than other older parts, but the potassium behavior is not changed since their ions remain being absorbed by roots from soil. This caesium behavior suggests that there is an amount of radiocaesium in the body of the plant that remains retained in the main trunk and that just ends up by the physical decay of ${ }^{137} \mathrm{Cs}$. For the chili pepper tree the enhancement observed for the potassium concentrations was due to the different concentrations in the transplantation soil, increasing the availability of potassium to the plant.

TABLE I: Mean values of ${ }^{137} C s$ and ${ }^{40} K$ concentrations for the younger and older parts of the tropical plants contaminated by caesium and for decontaminated plants. Values in parentheses represent the standard deviation from the mean.

\begin{tabular}{|c|c|c|c|}
\hline \multirow[t]{2}{*}{ Tree } & \multirow[t]{2}{*}{ Sample } & \multicolumn{2}{|c|}{$\begin{array}{l}\text { Mean values of concentrations } \\
\qquad\left(\mathrm{kBq} \cdot \mathrm{kg}^{-1}\right)\end{array}$} \\
\hline & & ${ }^{137} \mathrm{Cs}$ & ${ }^{40} K$ \\
\hline \multicolumn{4}{|c|}{ Contaminated plants by cesium } \\
\hline \multirow{4}{*}{ Guava } & Roots & $0.8(0.1)$ & $0.4(0.1)$ \\
\hline & Main trunk & $0.9(0.2)$ & $0.4(0.1)$ \\
\hline & Leaves & $2.1(0.3)$ & $0.7(0.1)$ \\
\hline & Fruits & $2.0(0.4)$ & $0.9(0.1)$ \\
\hline \multirow{3}{*}{ Mango } & Main trunk & $1.0(0.1)$ & $0.15(0.02)$ \\
\hline & Leaves & $1.9(0.6)$ & $0.32(0.05)$ \\
\hline & Fruits & $3.2(0.4)$ & $0.27(0.04)$ \\
\hline \multirow{2}{*}{ Avocado } & Main trunk & $1.8(0.4)$ & $0.23(0.04)$ \\
\hline & Leaves & $2.3(0.2)$ & $0.4(0.1)$ \\
\hline \multirow{4}{*}{ Chili pepper } & Roots & $2.1(0.2)$ & $0.24(0.04)$ \\
\hline & Main trunk & $1.1(0.1)$ & $0.21(0.03)$ \\
\hline & Leaves & $6.1(0.5)$ & $0.93(0.01)$ \\
\hline & Fruits & $2.5(0.3)$ & $0.48(0.13)$ \\
\hline \multirow{4}{*}{ Papaya } & Roots & $1.0(0.4)$ & $2.0(0.5)$ \\
\hline & Main trunk & $0.6(0.2)$ & $1.4(0.5)$ \\
\hline & Leaves & $0.4(0.1)$ & $1.6(0.2)$ \\
\hline & Fruits & $0.5(0.3)$ & $1.7(0.5)$ \\
\hline \multirow{3}{*}{ Manioc } & Roots & $0.12(0.04)$ & $0.22(0.02)$ \\
\hline & Main trunk & $0.21(0.06)$ & $0.14(0.22)$ \\
\hline & Leaves & $0.36(0.09)$ & $0.15(0.03)$ \\
\hline \multicolumn{4}{|c|}{ Decontaminated Plants } \\
\hline \multirow{5}{*}{ Chili pepper } & Roots & $0.13(0.01)$ & $0.45(0.05)$ \\
\hline & Main trunk & $0.28(0.02)$ & $0.50(0.06)$ \\
\hline & Twigs & $0.08(0.01)$ & $1.2(0.2)$ \\
\hline & Leaves & $0.04(0.01)$ & $2.2(0.4)$ \\
\hline & Fruits & $0.01(0.01)$ & $1.2(0.2)$ \\
\hline \multirow{5}{*}{ Pomegranate } & Roots & $1.2(0.1)$ & $0.13(0.01)$ \\
\hline & Main trunk & $0.8(0.1)$ & $0.09(0.01)$ \\
\hline & Twigs & $0.19(0.04)$ & $0.19(0.02)$ \\
\hline & Leaves & $0.34(0.06)$ & $0.54(0.06)$ \\
\hline & Fruits & $0.23(0.02)$ & $0.47(0.06)$ \\
\hline
\end{tabular}

Figure 2 shows conventional one-dimensional radial distributions of both elements within the tree rings in the main

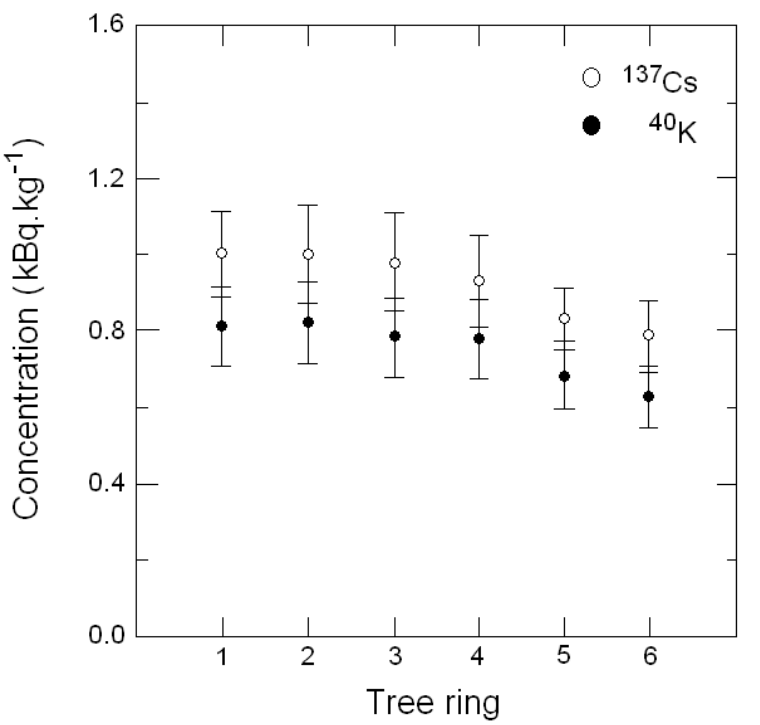

FIG. 2: Radial distribution of mean values of ${ }^{137} C s$ and ${ }^{40} K$ concentrations within the tree rings in the main trunk of a guava tree.

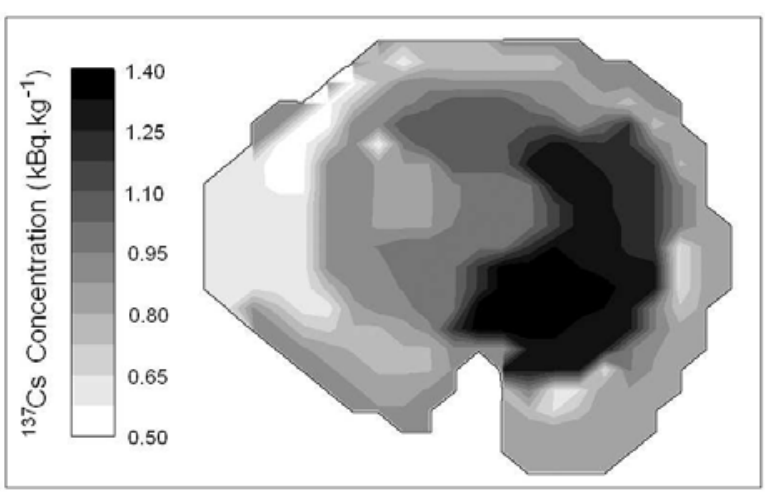

FIG. 3: Bi-dimensional diagram of the radial distributions of ${ }^{137} \mathrm{Cs}$ concentration mean values within the tree rings in main trunk of the guava tree (same of Fig. 2).

trunk of a guava tree. From this figure, one notices that allegedly both ${ }^{137} \mathrm{Cs}$ and ${ }^{40} \mathrm{~K}$ are concentrated inside the trunk, and they have similar behavior. However, the bi-dimensional diagrams allow observing interesting details that cannot be noticed in the one-dimensional distributions. For instance, the bi-dimensional diagram of ${ }^{137} C s$ radial distribution in the same main trunk presented in Fig. 3, shows that radiocaesium can be mobile, migrating within the rings, and tending to the side most exposed to sunlight. Although such behavior had already been observed for other plant species $[1,2,6]$, its origin is still not clear. In order to improve the understanding of such issue more experimental investigations would be of great importance. For potassium, on the other hand, the performed analysis did not show the same pattern, since distributions of ${ }^{40} \mathrm{~K}$ remained concentrated inside the trunk. In this way, the results suggest that although the two elements may have physicochemical similarities, they do not always behave alike. 

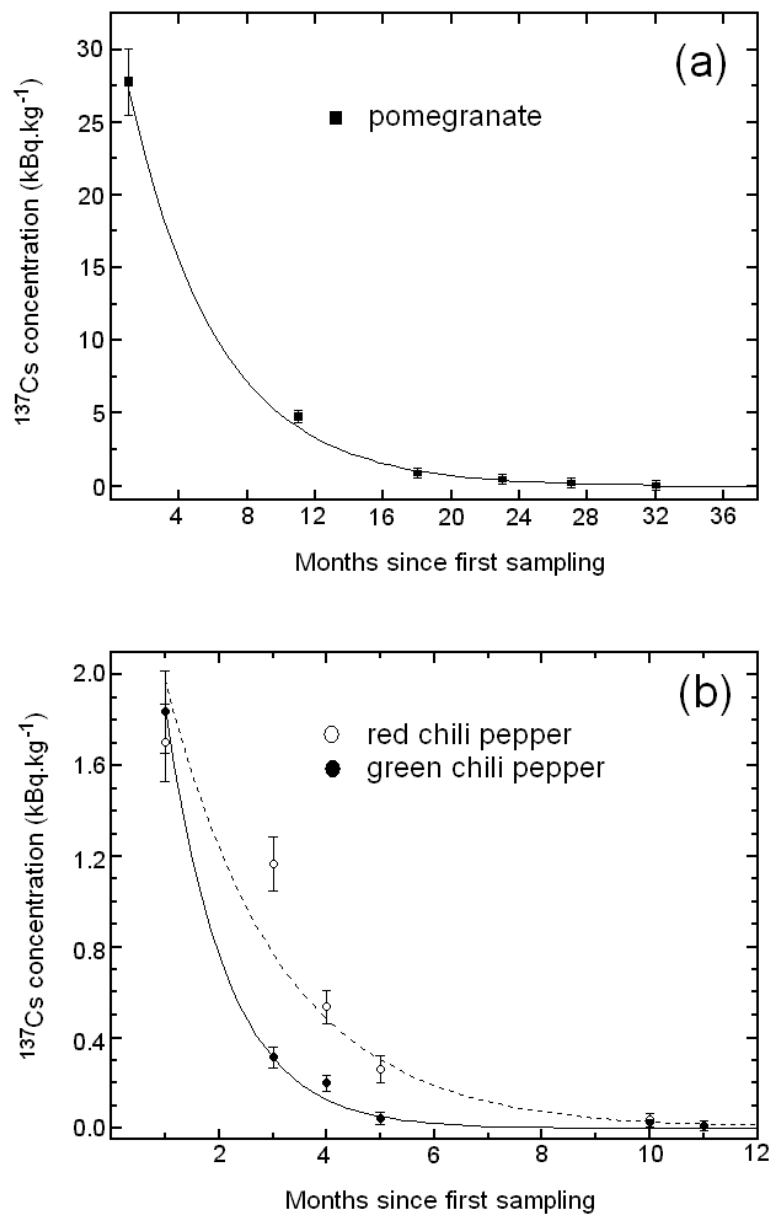

FIG. 4: Time dependence of ${ }^{137} \mathrm{Cs}$ concentrations: a) in pomegranate fruits, for which the solid line represents a single exponential function fit, providing a $\lambda_{T}$ value of $0.19 \pm 0.01$ month $^{-1}$. The fruits samplings consisted on five replicates of one fruit each. The error bars represent the standard deviation of the mean; b) in green and red chili peppers, for which the solid and dotted lines represent single exponential function fits, providing $\lambda_{T}$ values of $0.89 \pm 0.06$ month $^{-1}$ and $0.47 \pm 0.02$ month $^{-1}$ for green and red chili peppers, respectively. About 100 units of green and red chili peppers were collected from each sampling, resulting in 3 replicates from each of them. The error bars represent the standard deviation of the mean.

So, even though Cs and K show a similar behavior along wood plants, there are subtle differences between them that should be taken into account if radiocaesium is to be used to trace the plant uptake of nutrients such as $K^{+}$. The biological half-life of ${ }^{137} \mathrm{Cs}$ can be evaluated from Fig. 4 a for pomegranate and Fig. $4 \mathrm{~b}$ for both red and green chili peppers, because the main source of the contamination of new leaves and fruits was the fraction of the available radiocaesium in the body of the plant. It is expected for ${ }^{137} \mathrm{Cs}$ concentrations to decrease faster than its physical half-life because of the loss of ${ }^{137} \mathrm{Cs}$ by leaves or fruits, plant growth, transfer back to the soil, etc. This loss can be estimated using a compartment model for longterm radiocaesium contamination of fruit trees proposed by Antonopoulos-Domis et al. [7]. According to this model, the loss of ${ }^{137} C s$ concentration in fruits or leaves can be described by the sum of two exponentials:

$$
C^{C s}(t)=A \cdot e^{-\lambda_{T} \cdot t}+B \cdot e^{-\lambda_{U} \cdot t}
$$

where, A, B, $\lambda_{T}>0$ and $\lambda_{U}>0$ are constants. The first term of Equation (1) corresponds to the translocation of cesium from the tree reservoir, and the second is due to root uptake. Given that this experiment was performed with the aim of investigating how a fraction of the available radiocaesium in the body of the plant can be redistributed to other permanent organs, the second term can be neglected.

From $\lambda_{T}$ there were obtained the following biological halflife values due to ${ }^{137} \mathrm{Cs}$ translocation from the tree reservoir $\left(B H L_{T}\right): 0.30,0.12$ and 0.07 years for pomegranate and red and green peppers, respectively. It is interesting to note that the $\left(B H L_{T}\right)$ of pomegranate is about 100 times lower than the physical decay constant of ${ }^{137} C s\left(\mathrm{~T}_{1 / 2}=30.2\right.$ years $)$. In the case of chili peppers this ratio is 250 times lower. Knowing the rate at which such contaminant decline within various ecosystems components can be important for evaluating the length and severity of potential risks to resident species.

\section{CONCLUSIONS}

Our results have shown that ${ }^{137} C s$ and ${ }^{40} K$ have similar distributions among some tree compartments. However, establishing the suitability of radioactive isotopes to trace plant uptake of nutrients is still an unsolved problem, and detailed studies for the development of this technique are still required.

The study of biological half-life due to ${ }^{137}$ Cs translocation from the tree reservoir indicates that its values are of the order of months. Such information is important for the reclaiming of agricultural ecosystems after nuclear fallout. Knowing how tropical trees decontaminate after a period of growth in a ${ }^{137} \mathrm{Cs}$ contaminated area could be of interest in terms of risk assessment, and in terms of understanding the process involved in translocation of small ions in tropical or subtropical species.

\section{Acknowledgments}

The authors would like to thank the Brazilian funding agencies FAPERJ, CNPq and CAPES for their financial support. 
[2] B. Mosquera, C. Carvalho, R. Veiga, L. Mangia, and R. M. Anjos, Environmental and Experimental Botany 55, 273 (2006).

[3] C. Carvalho, B. Mosquera, R. Veiga, and R. M. Anjos, Braz. J. Phys. 35, 808 (2005).

[4] C. Carvalho, R. M. Anjos, B. Mosquera, K. Macario, and R. Veiga, Environmental Radioactivity 86, 241 (2006).

[5] Y-G. Zhu and E. Smolders, Journal of Experimental Botany 51,
1635 (2000).

[6] R. M. Anjos, N. K. Umisedo, A. Facure, E. M. Yoshimura, P. R. S. Gomes, and E. Okuno, Radiation Protection Dosimetry 101, 201 (2002).

[7] M. Antonopoulos-Domis, A. Clouvas, and A. Gagianas, Health Physics 58, 737 (1990). 